\section{Pancreatic cancer: surgical management and outcomes after 6 years of follow-up}

TO THE EDITOR: Speer and colleagues' recent article concerning pancreatic cancer outcomes makes sobering reading. ${ }^{1}$ Notwithstanding the results of surgery being in line with other case series, they found a somewhat high rate (nearly $40 \%$ ) of positive resection margins in patients undergoing surgery with curative intent. The authors also cite evidence from other studies indicating benefit from a small number of surgeons each performing a large volume of resections.

I would also argue for superspecialisation on the part of the other treating specialists; in particular, radiologists, nuclear medicine specialists, oncologists, radiotherapists and gastroenterologists. Rapid collection and evaluation of high-quality data regarding patients with pancreatic cancer are important if complications related to their treatment are to be avoided. Mandating multidisciplinary meetings, as occurs in Western Australia, may be useful, although the value of such meetings very much depends on the commitment, expertise and, to some extent, personality of the participants.

Speer et al's study is a salutary reminder that, despite our expanded knowledge base and advances in surgery and other therapeutic modalities, pancreatic cancer remains a cruel disease with an appalling prognosis. The least we can do for these patients is to avoid complications related to their therapy.

Andrew A Thomson Gastroenterologist

The Canberra Hospital, Canberra, ACT. andrew.thomson@act.gov.au

Competing interests: No relevant disclosures. doi: 10.5694/mjal2.10841

1 Speer AG, Thursfield VJ, Torn-Broers Y, Jefford M. Pancreatic cancer: surgical management and outcomes after 6 years of follow-up. Med $J$ Aust 2012; 196: 511-515. pancreatic cancer remains a cruel disease with an appalling prognosis

Thomson 